\title{
Analysis of information industry’s influence on manufacturing industry in China
}

\author{
Xiaodong $\mathrm{Yu}$ \\ School of Economics and Management, Beijing JiaoTong University \\ Beijing JiaoTong University, BJTU, Beijing, China \\ *Corresponding author: Xiaodong Yu, yxd450658621@163.com
}

\begin{abstract}
Information industry has become the pillar industry of a country .Information Industry's rise and fall decide the change of the whole economy. "Made in China 2025" project indicates the directions of manufacturing industry in China, information industry has important influence on the growth of manufacturing industry. This paper analyzes the function of our country's information industry in the growth of manufacturing industry from 2001 to 2015, using time sequence economic measuring method and it improves that information industry has Granger influence on the growth of manufacturing industry.
\end{abstract}

Keywords: information industry; Made in China 2025; VAR model; granger causality test

\section{Research background}

The manufacturing industry is an important component of our national economy. As a pillar industry of the national economy, it has become the basis and important support for China's national economic development. Since the founding of PRC in 1949, China's manufacturing industry has started from scratch, and an independent and complete manufacturing system has been established after thirty years of development. Since the implementation of the reform and opening policy in 1978, China's manufacturing industry has taken off rapidly, and to the first ten years of twenty-first century, China has become the world's largest manufacturing country ${ }^{1}$. However, China can only be called "manufacturing country" rather than "manufacturing power", for such disadvantages as serious energy consumption and pollution, weak original creative ability, poor product core competitiveness have seriously restricted the Chinese manufacturing industry when compared with advanced manufacturing industries in Europe and the United States, thus, the direction and approach of the development of China's 
manufacturing industry has always been the focus of government decision-making departments and academia. Premier Li Keqiang pointed out that it was urgent to implement the "made in China 2025" strategy and accelerate the shift from manufacturing country to manufacturing power in his report on government work on March 5, $2015^{2}$."Made in China 2025" can be regarded as China's "Industry 4.0”. This strategy put forward the mission of promoting China's manufacturing industry to the medium and high-end development. It also is China's attempt and effort to upgrade to the manufacturing power from a big manufacturing country. The main task of the plan of "Made in China 2025" is to realize the deep integration of information technology and industrialization to develop digital, networked and intelligent manufacturing to transform and upgrade China's manufacturing industry.

Information technology can be regarded as the most concerned technology at present and has become the driving force of the new generation of industrial revolution. As the leading industry of current national economy, the information technology industry has become the motive force for the development of other industrial sectors and the basis of social reproduction, at the same time, it is also the leading industry that drives other hi-tech industries to take off. Meanwhile, experience of overseas development shows that the information technology industry is the key factor to promote economic growth and industrial transformation and upgrading.

\section{Literature review}

Domestic scholars have done a lot of empirical analysis on the role and influence of information industry on economic growth and industrial development. Xue Jingxiao and Zhang Bing (2003) used a large amount of data on the development of the information industry and the macro economy in the United States to analyze that the information technology industry had become the leading industry of the American economy. Because of the development of information, regulation on the economy in America was also more effective ${ }^{3}$. Xu Shenghua and Mao Xiaobing (2004) started from economic growth theory, and used the basic form of Solow model and the method of regression analysis to approve that the growth of China's industry was mainly driven by technological progress, and the contribution rate of technological progress had reached $64 \%$. They further pointed out the concept of "the richness of information resources”, and through regression analysis, it was pointed out that information factors had positive effects on economic growth ${ }^{4}$. Wang Hongwei (2009) calculated the TFP growth rate of the information industry, the results showed that the 
information industry had made great contribution to economic growth, and the development of information industry was also the driving force for the optimization and adjustment of industrial structure, meanwhile, he also put forward suggestions for actively developing the information industry ${ }^{5}$. He Qiang (2012) made a regression analysis on the panel data of China and its provinces from 2000-2010, and he found that the development of information technology industry had a significant and positive effect on economic growth, and there was threshold effect; at the same time, he also pointed out that the contribution of information industry to economic growth had not reached a high level yet, China's information industry still had a lot of room for development ${ }^{6}$.

\section{Relationship between information industry and the development of manufacturing industry}

As we all know, IT industry contains different industry contents under different caliber. In the current researches, the information industry is usually divided into two parts: one is departments engaged in the production of computers, electronics and communications equipment; the other is industrial sectors engaged in the provision of information services. The influence of information technology industry on the development of manufacturing industry is mainly affected by two aspects, the direct and indirect influence.

\subsection{Direct influence of information industry on the development of manufacturing industry}

One of the most important components of the IT industry is the computer, electronics and communications equipment manufacturing industry, it is also a major component of the manufacturing sector. According to data from the National Bureau of Statistics in 2015, the industrial sales output value of computer, electronics and communication equipment manufacturing industry was 9 trillion and 137 billion 886 million yuan, leading the manufacturing sector, with a year-on-year growth of $7.16 \%$, which was higher than the manufacturing average rate and GDP growth rate. Thus, the computer, electronics and communication equipment manufacturing industry is the most dynamic part of the current national economy. Meanwhile, with the upgrading of products, many products of the computer, electronic and communication equipment manufacturing industry have become the necessary raw materials for manufacturing in other manufacturing industries ${ }^{7}$. It can be said that the development of manufacturing industry is closely depend on the development of information industry. 


\subsection{Indirect influence of information industry on the development of manufacturing industry}

The impact of the information industry on the manufacturing sector is also reflected in the transformation and upgrading in all aspects of the manufacturing sector. The impact of information technology on the manufacturing sector, in particular, can be reflected mainly through the following aspects: reducing manufacturing marketing and management costs; improving manufacturing management and quality management system; promoting innovation in manufacturing production patterns and productivity improvements ${ }^{8}$; promoting the intellectualization of manufacturing products; promoting the increase in traditional manufacturing services; promoting innovation capability of manufacturing cluster; accelerating manufacturing industry to achieve green manufacturing ${ }^{9}$. Because of the application of information technology, the manufacturing industry has also begun to transform: mass customization beginning to replace mass production; rise of service sector in manufacturing industry; transformation from universal manufacturing to network manufacturing and cloud manufacturing; retail and agent Internet oriented. Therefore, it can be said that the information industry will promote a new revolution in the manufacturing sector.

\section{Empirical analysis based on VAR model}

After the text edit has been completed, the paper is ready for the template. Duplicate the template file by using the Save As command, and use the naming convention prescribed by your conference for the name of your paper. In this newly created file, highlight all of the contents and import your prepared text file. You are now ready to style your paper; use the scroll down window on the left of the MS Word Formatting toolbar.

\subsection{Data acquisition and stationarity test}

There is less statistics data on IT industry among current data from China's Statistics Divisions. Therefore, this paper refers the method adopted by Xu Shenghua (2004) and Zhang An (2006) ${ }^{10}$, using the data of gross output value of computer, electronic and communication equipment manufacturing, business of Posts and Telecommunications, and sales revenue of software and services to approximately substitute IT industry data. The variable IT represents the total industrial output value of the computer, electronic and communication equipment manufacturing industry, the total number of Posts and telecommunications business and the 
sum of sales revenue of software and service industry, and the variable ZZ represents the gross output value of China's manufacturing industry. Sample data are available from 2001 to 2015. Data needed are sorted out according to China Statistical Yearbook 2002-2016, China Industrial Statistics Yearbook 2002-2015, China Electronic Information Industry Yearbook 2003-2015.

Before the model is established, the stationarity of the variable sequence should be examined. Because most of the economic data in reality are non-stationary, the natural logarithm sequence of the IT and ZZ is represented by the method of taking the logarithm of the natural number to the data. The results of ADF test are as follows Table 1:

Table 1-ADF test result

\begin{tabular}{|c|c|c|c|}
\hline \multirow{2}{*}{$\begin{array}{l}\text { ADF } \\
\text { TEST }\end{array}$} & \multicolumn{3}{|c|}{ RESULT } \\
\hline & & LIT & LZZ \\
\hline & & $\begin{array}{l}\text { t-Statistic } \\
\text { (Prob.) }\end{array}$ & $\begin{array}{l}\text { t-Statistic } \\
\text { (Prob.) }\end{array}$ \\
\hline & $\begin{array}{l}\text { Augmented Dickey-Fuller test } \\
\text { statistic }\end{array}$ & $\begin{array}{c}-3.660932 \\
(0.0185)\end{array}$ & $\begin{array}{c}-8.272570 \\
(0.0000)\end{array}$ \\
\hline & Test critical values: $1 \%$ level & -4.004425 & -4.121990 \\
\hline & Test critical values: $5 \%$ level & -3.098896 & -3.144920 \\
\hline & Test critical values: $10 \%$ level & -2.690439 & -2.713751 \\
\hline
\end{tabular}

According to the test results, the natural logarithm sequence of the variable is stationary and can be used for regression analysis.

\subsection{Co-integration test}

The cointegration relationship can be defined in the following mathematical language: Suppose two time series variables $x_{t}, y_{t}$, and these two variables are all I (1) process. If a linear combination of $\mathrm{x}_{\mathrm{t}}$ and $\mathrm{y}_{\mathrm{t}}$, such as $\mathrm{x}_{\mathrm{t}}-\mathrm{by}_{\mathrm{t}}$, constitutes a stationary time series, we can say that $x_{t}$ and $y_{t}$ have cointegration relationship and the cointegration vector is [ $1-b$ ]. Cointegration was first defined in the study of Granger (1981), and then many famous economists in the world made the cointegration test and the rapid development and application of cointegration through continuous research. Among them the most famous are Granger (1983), Engle and Granger (1987), Stock and Wat (1988), Johansen (1988, 1991 and 1994) and others.

Cointegration test is a concept in statistics, but the cointegration relationship has a rich economic significance. If there is a cointegration relationship between the variables studied, it 
can be said that there is a long - run relationship or equilibrium relationship between these variables. Therefore, the cointegration relationship depicts the long-term equilibrium relationship between the relevant economic variables, which is of great significance to the economic research.

The cointegration test usually selects Johansen and Juselius (1990) for cointegration test. The test results are shown in Table.2. The test shows that there is a cointegration relationship under the significant level of $1 \%$ and $5 \%$ :

Table 2-Unrestricted cointegration test result

\begin{tabular}{|c|c|c|c|}
\hline \multirow{2}{*}{ TEST } & \multicolumn{3}{|c|}{ RESULT } \\
\hline & \multicolumn{3}{|c|}{ Unrestricted Cointegration Rank Test (Trace) } \\
\hline \multirow{7}{*}{$\begin{array}{c}\text { Cointegration } \\
\text { Test }\end{array}$} & $\begin{array}{c}\text { Hypothesized } \\
\text { No. of CE(s) }\end{array}$ & $\begin{array}{c}0.05 \\
\text { Critical Value }\end{array}$ & Prob. \\
\hline & None & 15.49471 & 0.0183 \\
\hline & At most 1 & 3.841466 & 0.0166 \\
\hline & \multicolumn{3}{|c|}{ Unrestricted Cointegration Rank Test (Maximum Eigenvalue) } \\
\hline & $\begin{array}{l}\text { Hypothesized } \\
\text { No. of CE(s) }\end{array}$ & $\begin{array}{c}0.05 \\
\text { Critical Value }\end{array}$ & Prob. \\
\hline & None & 14.26460 & 0.0910 \\
\hline & At most 1 & 3.841466 & 0.0166 \\
\hline
\end{tabular}

\subsection{VAR model}

The essence of vector autoregressive (VAR) model is to examine the dynamic interaction among multiple variables. If the object of research is a group of time series variables $y_{1}$ t $\mathrm{y}_{2}, \ldots \mathrm{y}_{\mathrm{n}}$, these variables can be defined as $\mathrm{Y}_{\mathrm{t}}=\left[\mathrm{y}_{1}, \mathrm{y}_{2 \mathrm{t}}, \ldots \mathrm{y}_{\mathrm{nt}}\right]^{\mathrm{T}}, \mathrm{t}=1,2, \ldots \mathrm{T}$.

Because the natural logarithm sequence of the study object sequence is stable and there exists cointegration relationship, the VAR model is established, and the estimation results are shown in Table 3.

\subsection{Causality test}

Granger proposed a test to judge the causal relationship, which is Granger causality test. Granger causality can be used to test whether all the lag items of a variable have an impact on the current value of another or several variables. Precisely, in the VAR model, Granger causality is to judge whether a variable can be used to improve the "forecast" ability to other related variables. 
Table 3-Vector autoregression estimates

\begin{tabular}{|c|c|c|c|}
\hline \multirow{2}{*}{ VAR } & \multicolumn{3}{|c|}{ RESULT } \\
\hline & & LIT & $\overline{L Z Z}$ \\
\hline \multirow{15}{*}{ Estimates } & $\operatorname{LIT}(-1)$ & $\begin{array}{c}0.766298 \\
(0.31145) \\
{[2.46039]}\end{array}$ & $\begin{array}{c}0.563719 \\
(0.40204) \\
{[1.40214]}\end{array}$ \\
\hline & LIT(-2) & $\begin{array}{c}-0.028390 \\
(0.31763) \\
{[-0.08938]}\end{array}$ & $\begin{array}{c}-0.086190 \\
(0.41001) \\
{[-0.21021]}\end{array}$ \\
\hline & LZZ(-1) & $\begin{array}{c}-0.231277 \\
(0.26162) \\
{[-0.88402]}\end{array}$ & $\begin{array}{c}0.116464 \\
(0.33771) \\
{[0.34486]}\end{array}$ \\
\hline & LZZ(-2) & $\begin{array}{c}0.302118 \\
(0.20644) \\
{[1.46345]}\end{array}$ & $\begin{array}{c}0.413429 \\
(0.26649) \\
{[1.55141]}\end{array}$ \\
\hline & $\mathrm{C}$ & $\begin{array}{c}2.153407 \\
(0.57713) \\
{[3.73125]}\end{array}$ & $\begin{array}{c}1.067028 \\
(0.74499) \\
{[1.43227]}\end{array}$ \\
\hline & R-squared & 0.983668 & 0.986299 \\
\hline & Adj. R-squared & 0.975501 & 0.979448 \\
\hline & Sum sq. resids & 0.047712 & 0.079503 \\
\hline & S.E. equation & 0.077227 & 0.099689 \\
\hline & F-statistic & 120.4556 & 143.9710 \\
\hline & Log likelihood & 18.00265 & 14.68370 \\
\hline & Akaike AIC & -2.000408 & -1.489800 \\
\hline & Schwarz SC & -1.783120 & -1.272512 \\
\hline & Mean dependent & 11.06018 & 13.01339 \\
\hline & S.D. dependent & 0.493400 & 0.695376 \\
\hline
\end{tabular}

The VAR model is:

$\operatorname{lzz}=1.067+0.5637 \operatorname{lit}(-1)-0.0862 \operatorname{lit}(-2)+0.1165 \mathrm{lzz}(-1)+0.4134 \mathrm{lzz}(-2)$

lit=2.1534+0.7663lit(-1)-0.0284lit(-2)-2313lzz(-1)+0.3021lzz(-2)

From the above, the information industry has positive correlation to the manufacturing industry, the elasticity of the information industry is $56.37 \%$, the elasticity of the information industry lag phase ii to the manufacturing industry is - $8.62 \%$, and the comprehensive elasticity is $47.75 \%$.

Granger causality test can be defined as: if the mean square error of $\mathrm{y}_{\mathrm{t}+\mathrm{s}}$ predicted based on $\left(\mathrm{y}_{\mathrm{t}}, \mathrm{y}_{\mathrm{t}-1}\right)$ is equal to the one predicted based on $\left(\mathrm{y}_{\mathrm{t}}, \mathrm{y}_{\mathrm{t}-1}\right)$ and $\left(\mathrm{x}_{\mathrm{t}}, \mathrm{x}_{\mathrm{t}-1}\right)($ all $\mathrm{s}>0)$, then $\mathrm{y}$ is not caused by $\mathrm{x}$. If $\mathrm{x}$ is helpful in the prediction of $\mathrm{y}$, or when the correlation coefficient of $\mathrm{x}$ and $y$ is statistically significant, it can be said that " $\mathrm{x}$ is the Granger cause of $\mathrm{y}$ ". 
The lit and lzz sequences were tested by Eviews 9.0 software, and the results are as shown in Table 4:

Table 4-Pairwise granger causality tests result

\begin{tabular}{|c|c|c|c|}
\hline \multirow{2}{*}{ CAUSALITY } & \multicolumn{2}{|c|}{ RESULT } \\
\cline { 2 - 4 } & Null Hypothesis & F-Statistic & Prob. \\
\hline \multirow{2}{*}{} & LZZ does not Granger Cause LIT & 0.00730 & 0.9334 \\
\cline { 2 - 4 } & LIT does not Granger Cause LZZ & 4.85075 & 0.0499 \\
\hline
\end{tabular}

The result of the test shows that the information industry is the Granger cause of the manufacturing industry under the 95\% confidence level in the lag period of 1 .

\section{Conclusions}

The information technology industry has promoted the development of manufacturing industry. From the VAR model, it can be concluded that the development of the information technology industry has a positive impact on the development of manufacturing industry. The Granger causality test also proves the role of the information technology industry in promoting the development of the manufacturing industry.

The development of information technology industry and manufacturing industry is lack of synchronization. When the lag time is longer, the correlation between them is weaker.

In order to realize the healthy and sustainable development of manufacturing industry, to achieve the "Made in China 2025" planning and the advanced nature of manufacturing industry, it must be speed up the construction of information technology industry. The development planning of information industry should be improved, and the development direction and target of information industry should be clear. Establish and improve laws and regulations, protect intellectual property rights of information technology, and create a favorable legal environment for the sustained and healthy development of information technology industry. Promote education reform, strengthen discipline construction and cultivate talents of information technology industry. Accelerate the adjustment of the internal structure of the information industry, support the software and information services industry, enhance the development and design and innovation capacity of the industry, and promote the information technology to achieve a leapfrog development. 


\section{Acknowledgment}

Many people have offered me valuable help in my thesis writing, including my tutor, my classmates and my parents.

Firstly, I would like to give my sincere gratitude to my tutor, who gave me great help by providing me with necessary materials, advice of great value and inspiration of new ideas with extraordinary patience and consistent encouragement. Then, I am extremely grateful for my classmates for their invaluable assistance throughout the preparation of the original manuscript. Finally, in particular, I would like to express my express my gratitude to my parents for their support. They provided the computer for me to search for information. It is of great help for me to finish this thesis successfully.

\section{References}

1. C. X. Guo, H. X. Wang, "The development of Chinese manufacturing industry and the "Made in China 2025" plan,” Review of Economic Research. Beijing, vol. 31, pp. 313, August 2015.

2. J. Zhou, "Intelligent manufacturing - the main direction of "Made in China 2025"” China Mechanical Engineering. Wuhan, vol. 17, pp. 2273-2284, September 2015.

3. J. X. Xue, B. Zhang, "The role of information technology industry in the new cycle of the United States” Nankai Economic Studies. Tianjin, vol. 3, pp. 3-9, April 2003.

4. S. H. Xu, X. B. Mao, "Analysis of the contribution of information industry to economic growth” Management World. Beijing, vol. 8, pp. 75-80, August 2004.

5. H. W. Wang, “An Empirical Analysis of Information Technology lndustry and Chinese Economic Growth” China Industrial Economics. Beijing, vol. 11, pp. 66-76, November 2009.

6. Q. He, "Analysis of the Threshold Effects and Dynamic Effects of Information Technology Industry Development on Economic Growth,” Industrial Economics Research. Nanjing, vol. 5, pp. 11-18, October 2012.

7. S. X. Li, Z. S. Huang, "The Relational Analysis and Empirical Research on Information Industry and Advanced Manufacturing Industry” Chinese Journal of Management Science. Beijing, vol. 21, pp. 587-593, November 2013.

8. X. Z. Li, D. Y, "Study on the Coupling Development between Automobile Industry and Electronic Information Industry in China” Soft Science. Sichuan, vol. 30, pp. 19-23, November 2016. 
9. X. Z. Li, H. L. Chen, "Research on the Industrial Performance of the Convergence of Information Industry with Manufacturing Industry Based on the Data of Zhejiang Province” China Soft Science. Beijing, vol. 1, pp. 22-30, January 2017.

10. Z. An, "Positive study on the influence of information industry on economic growth" Information Technology. Heilongjiang, vol. 7, pp. 140-144, July 2006. 